\title{
MENJAGA KEHORMATAN SEBAGAI PERLINDUNGAN NASAB PERSPEKTIF MAQASHID SYARI'AH
}

\author{
M. Lutfi Khakim \\ Institut Agama Islam Negeri Metro, Lampung \\ Email: kanjenghakim@gmail.com \\ Mukhlis Ardiyanto \\ Institut Agama Islam Negeri Jember \\ Email: mukhlis0319@gmail.com
}

\begin{abstract}
Allah created humans with perfect and honorable nature from other creatures. But the honor that is bestowed must be guarded with respectable behavior. both household building honor or personal respect need to be maintained for the creation of quality offspring in accordance with the concept of maqashid asy-shari'ah, one of which is to maintain nasab hifdz nasl. Today guarding the respect of the offspring both in terms of concept or practice, began to be eroded by freedom and Westernization. This study uses library research library research methods, the data used are secondary data that is data obtained by studying library materials in the form of books, documents, regulations, research results, archives and as related to the problems in question. researched. The results of this study indicate that Islam is very careful in maintaining the nasab and honor of each adherent. And do not recommend to damage the honor and one's descendants. All forms of behavior that damage honor and offspring are strictly forbidden and even Islam is firm in providing sanctions for violators.
\end{abstract}

Keywords: Maintaining Honor, Protection of the Nasab, Maqashid Shari'ah.

\section{A. Pendahuluan}

Teori maqashid asy-syari'ah, Dalam kajian hukum Islam yaitu tujuan tujuan mendasar diberlakukanya ajaran agama Islam atau tujuan pemberlakuan hukum Islam. Inti dari teori maqashid asy-syari'ah berupa makna dan tujuan yang dikehendaki oleh syara' dalam mensyariatkan suatu hukum bagi kemaslahatan umat manusia. Teori ini dikalangan ulama ushul fiqh juga disebut dengan asrar asy-syari'ah, yaitu rahasia-rahasia yang terkandung dibalik hukum yang ditetapkan oleh syara' berupa kemaslahatan bagi umat manusia, baik di dunia maupun di akhirat. Dalam hal ini ajaran Islam dengan konsep maqashid asy-syari' ahnya sangat mementingkan pemeliharaan terhadap lima prinsip, yaitu agama, jiwa, akal, keturunan, dan harta.

Tujuan umum syar'i dalam mensyari'atkan hukum hukumnya ialah mewujudkan kemaslahatan manusia dengan menjamin hal-hal yang dhoruri atau kebutuhan pokok, pemenuhan kebutuhan merek atau hajiyat, dan kebaikan kebaikan mereka atau tahsiniyat. ${ }^{1}$ Setiap hukum syar'i tidaklah dikehendaki untuk dibuat kecuali didalam hukum syar'i tersebut mengandung salah satu dari tiga tersebut yang mana esensinya ialah untuk mencapai kemaslahatan bagi manusia. Seperti yang terlihat dalam kehidupan dewasa ini banyak sekali umat manusia dalam menjaga keberlangsungan entitas umat manusia tidak melihat

1Abdul Wahab Khalaf,Ilmu ushul figh, (Semarang: Toha Putra Group, 1994), h. 310. 
sisi nasabiahnya,dengan begitu dalam menjaga kehormatan manusia itu sendiri juga terabaikan.

Berbagai fenomena dewasa ini banyak keluarga yang tidak bisa mempertahankan kehormatan nasab atau keturunan, hal ini bisa dilihat dari banyak nya para orang tua yang abai terhadap para anaknya. Kalangan remaja banyak terjerembab kedalam pergaulan bebas, pacaran, hamil di luar nikah dan aborsi yang mana hal tersebut menjurus kepada perilaku merusak kehormatan dan keturunan.

Hal ini tentunya dapat merusak keturunan, atau dengan sekala besar lambat laun dapat merusak qualitas generasi muslim. Berangkat dari fenomena ini penulis mencoba menarik ulang konsep teori yang konstruktif mengenai menjaga kehormatan sebagai perlindungan nasab perspektif maqashid syari'ah.

\section{B. Metode Penelitian}

Kajian ini merupakan hasil penelitian kualitatif. Data dalam kajian ini berasal dari sumber data primer dan sumber sekunder. Adapun sumber primer dari penelitian ini adalah teks Alquan dan hadist, sedangkan sumber sekunder dari buku-buku terkait. Jadi penelitian yang peneliti lakukan adalah penelitian kepustakaan dimana peneliti mengkaji buku-buku atau literatur yang berhubungan dengan menjaga kehormatan sebagai perlindungan nasab perspektif maqashid syari'ah.

Analisa data dalam kajian ini menggunakan metode analisis isi (content analysis). Metode ini dioperasionalkan dengan membuat inferensi-inferensi yang dapat ditiru dan sahih data dengan memperhatikan konteksnya. ${ }^{2}$

Peneliti juga membuat kategori-kategori berbagai tema dan pola-pola tertentu dari data. Kategori-kategori tersebut dirumuskan berdasarkan catatan terhadap data yang ada. Pola analisis dalam kajian ini merupakan pola induktif, mengingat kajian ini merupakan kajian berdasarkan penelitian kualitatif. ${ }^{3}$ Dari sinilah penulis bisa membuat kesimpulan kajian yang obyektif dan dapat dipertanggungjawabkan, baik secara substantif maupun metodologis.

\section{Pembahasan}

\section{C.1. Pengertian Maqūṣid Syarī'ah}

Maqāṣid Syarī'ah secara etimologi (bahasa) terdiri dari dua kata, yakni maqasid dan syari'ah. Maqāṣid, adalah bentuk jamak dari maqsid, yang merupakan masdar dari kata (يقصد قصدا ومقصدا قصد),4 yang dapat diartikan dengan makna maksud atau tujuan. Sedangkan kata syari'ah, secara kebahasaaan kata syari'ah pada dasamya dipakai untuk sumber air yang dimaksudkan untuk diminum. Kemudian orang Arab memakai kata syari'ah untuk pengertian jalan yang lurus (الطر يقة المستقيمة).Hal itu adalah dengan memandang bahwa sumber air adalah jalan yang lurus yang membawa manusia kepada kebaikan. ${ }^{5}$

${ }^{2}$ Klaus Krippendorff, Content Analysis; an Indtroduction to Its Methodology (London: Sage Publication, 2004), h. 34.

${ }^{3}$ Norman K. Denzin dan Yvonna S. Lincoln, Hand Book of Qualitative Research (Yogyakarta: Pustaka Pelajar, 2009), h. 272.

${ }^{4}$ Hisyam bin Said Azhar, Maqhosid asy-Syariah inda Imam al-Haramain wa Atsaruha fi atTasorrufat al-Maliyyah, (Riyad: Maktabah ar-Rusyd, 2010), h. 23.

5Manna al-Qathtan, Tarikh Tasyri' al-Islami, (Kairo: Maktabah Wahbah, 2001), h. 13. 
Adapun pengertian Maqāṣid syari 'ahsecara istilah dikemukakan oleh beberapa ulama dengan ungkapan yang berbeda. Namun pengertian dalam ungkapan tersebut mengandung maksud yang sama, yaitu tentang tujuan atau maksud pensyari'atan hukum Islam. Hal itu dapat dilihat dari defenisi yang dikemukakan Thahir ibn 'Asyur dalam Hisyam bin Said Azhar sebagai berikut:

"Maqāṣid syari 'ah ialah makna-makna dan hukum yang diperhati- kan Syari' dalam sekalian keadaan dari pensyari'atan hukum atau sebagian besamya, yang tidak dikhususkan perhatian tersebut dengan keadaan pada satu macam tertentu dari hukumhukum syari'ah."

Definisi lain dikemukakan oleh al-Fasi, dalam Abd 'Athi' Muhammad sebagai berikut:

"Maqāṣid syari'ah adalah tujuan dari syari'at, dan rahasia-rahasia syari'at yang ditetapkan oleh Syari (Allah) dalam hukum-hukum syariat."

Berdasarkan uraian di atas, maqāșid asy- Syar ì'ah adalah tujuan Allah dan Rasul-Nya dalam merumuskan hukum-hukum Islam.Tujuan itu dapat ditelusuri dalam ayat-ayat al-Qur'an dan hadis sebagai alasan logis bagi rumusan suatu hukum yang berorientasi kepada kemaslahatan manusia.

Pengertian maqāṣid asy-Syarī'ah sebagaimana tersebut di atas mendorong para ahli hukum Islam untuk memberi batasan syariah dalam arti istilah yang langsung menyebut tujuan syariah secara umum. Hal ini dapat diketahui dari batasan yang dikemukakan oleh Syaltut dalam Abdul Manan bahva syariah adalah aturan-aturan yang diciptakan oleh Allah untuk dipedomani manusia dalam mengatur hubungan dengan Tuhan, manusia baik sesama Muslim maupun non-muslim, alam dan seluruh kehidupan. ${ }^{6}$

Kajian teori Maqāșid asy- Syar $\bar{i}^{\prime}$ ah dalam hukum Islam adalah sangat penting.Urgensi itu didasarkan pada pertimbangan-pertimbangan sebagai berikut.Pertama, hukum Islam adalah hukum yang bersumber dari wahyu Tuhan dan diperuntukkan bagi umat manusia. Oleh karena itu, ia akan selalu berhadapan dengan perubahan sosial. Dalam posisi seperti itu, apakah hukum Islam yang sumber utamanya (Al-Qur'an dan sunnah) turun pada beberapa abad yang lampau dapat beradaptasi dengan perubahan sosial. Jawaban terhadap pertanyaan itu baru bisa diberikan setelah diadakan kajian terhadap berbagai elemen hukum Islam, dan salah satu elemen yang terpenting adalah teori Maqāșid al-syari'ah .Kedua, dilihat dari aspek historis, sesungguhnya perhatian terhadap teori ini telah dilakukan oleh Rasulullah SAW, para sahabat, dan generasi mujtahid sesudahnya.Ketiga, pengetahuan tentang Maqāṣid al-syari'ah merupakan kunci keberhasilan mujtahid dalam ijtihadnya, karena di atas landasan tujuan hukum itulah setiap persoalan dalam bermu'amalah antar sesama manusia dapat dikembalikan. ${ }^{7}$

Menurut Abdul Manan teori maqāṣid al-syari'ah baru dikenal pada abad ke-41-Hijriah.Pertama kali istilah maqāșid al-syari'ah itu digunakan oleh Abu Abdalah al-Tirmizi al-Hakim dalam buku yang ditulisnya. Kemudian istilah maqashid ini dipopulerkan olch al-Imam al-Haramain al-Juaini dalam beberapa kitab yang ditulisnya dan beliaulah orang yang pertama mengkiasifikasikan

${ }^{6}$ Abdul Manan, Pembaruan Hukum Islam di Indonesia, (Jakarta: Kencana, 2017), h. 71.

7Ghofar Shidiq, TeoriMaqashid Al-Syari'ah Dalam Hukum Islam, Jurnal Sultan Agung, (Vol. XLIV No. 118 Juni - Agustus 2009), h. 120. 
maqāṣid al-syari'ah menjadi tiga kategori besar, yaitu: dharuriah, hajjiyah, dan tahsiniyyah. Pemikiran al-Juaini tentang maqāṣid al-syari'ah ini dikembangkan lebih lanjut oleh AbuHamid al-Ghazali yang menulis secara panjang lebar tentang maqashid maqāṣid al-syari'ah Kitabnya Shifa al-Ghalil dan al-Musthafa min 'Ilmi al-Ushul Kemudian al-Amidi menguraikan lebih lanjut tentang maqāșid al-syari'ah dengan berpedoman kepada prinsip dasar syariah, yaitu kehidupan, intelektual, agama, garis silsilah keturunan, dan harta kekayaan. Selanjutnya Maliki Shihab al-Din al-Qarafi menambah prinsip dasar syariah dengan prinsip perlindungan kehormatan (al- Ird).Pendapat ini didukung oleh Taj al-din Abdul Wahab Ibn al-Subqi dan Muhammad Ibn Ali al-Shoukani. ${ }^{8}$

Kajian Maqāșid asy- Syar î́ah kemudian dikembangkan secara luas dansistematis oleh Abu Ishaq al-Syathibi. Kajian tentang Maqāṣid asy- Syar ì'ah ini menurut al-Syathibi bertolak dari asumsi bahwa segenap syari'at yang diturunkan Allah senantiasa mengandung kemaslahatan bagi hamba-Nya untuk masa sekarang (di dunia) dan sekaligus masa yang akandatang (di akhirat). Tidak satupun dari hukum Allah yang tidak mempunyai tujuan. Hukum yang tidak mempunyai tujuan sama dengan taklif ma la yuthaq (pembebanan suatu yang tidak bisa dilaksanakan) yaitu dalam ungkapan imam Syathibi yang berbunyi:

"Sesungguhnya Syari' (pembuat hukum, yaitu Allah) menetapkan hukum adalah untuk kemaslahatan manusia untuk kehidupan sekarang (dunia) dan akhirat secara bersamaan antara keduanya."

\section{C.2. Maqāsid Syarī'ah Perlindungan Kehormatan}

Islam menjamin kehormatan manusia dengan memberikan perhatian yang sangat besar, yang dapat digunakan untuk memberikan spesialisasi kepada hak asasi mereka. Perlindungan ini jelas terlihat dalam sanksi berat yang dijatuhkan dalam masalah zina, menghancurkan kehormatan orang lain, dan masalah qadzaf. Islam juga memberikan perlindungan melalui pengharaman ghibah, mengadu domba, mengumpat, mencela dengan menggunakan panggilan buruk, juga perlindungan-perlindungan lain yang bersinggungan dengan kehormatan dan kemuliaan manusia. Diantara bentuk perlindungan yang diberikan adalah dengan menghinakan dan memberikan ancaman kepada para pembuat dosa dengan siksa yang sangat pedih pada hari kiamat. ${ }^{9}$ Dalam maqashid syariah di tingkat doruriyah beberapa ulama ushul menyebutkan bahwa irod atau kehormatan menjadi salah satu tujuan dari hukum Islam. Sehingga tidaklah mengherankan jika sebagian ahli ushul memasukkan al'ardh (harga diri) dan al'adl (keadilan). ${ }^{10}$

Tujuan Islam dalam menghormati asas kehormatan tercermin dalam hal Qadzaf. Qadzaf secara etimologi berarti melempar dengan kuat dan keras. Adapun melakukan qadzaf kepada orang yang sudah menikah (baik perempuan

8Abdul Manan, Pembaruan Hukum Islam di Indonesia..., h. 72.

${ }^{9}$ Ahmad Al-Mursi Husain Jauhar, Maashid Syariah,(Jakarta: Amzah, 2013), h. 131.

${ }^{10}$ Galuh Nashrullah Kartika Mayangsari R dan H. Hasni Noor, Konsep Maqashid Al-Syariah Dalam Menentukan Hukum Islam: Perspektif Al-Syatibi dan Jasser Auda, (Al-Iqtishadiyah, Vol. I, Issue I, Desember 2014), h. 63. 
maupun laki-laki) secara istilah ilmu fiqh berarti menuduhnya melakukan zina atau menafikan hubungan nasab anak kepada sang bapak. ${ }^{11}$

Syari'at Islam menetapkan, qadzaf adalah orang yang menjatuhkan kehormatan laki-laki atau wanita yang sudah menikah, dengan memberikan tuduhan zina, namun dia tidak dapat menghadirkan bukti pasti atas apa yang dikatakan atau dituduhkanya. Dalil atau bukti pasti yang diminta Islam dalam kasus ini sangat sulit dihadirkan, karena tuduhan tidak akan terealisasi melainkan dengan mendatangkan empat orang saksi yang benar benar adil, yang memberikan kesaksian bahwa dengan mata kepala sendiri mereka melihat perbuatan zina itu dilakukan dalam bentuk yang tidak ada keraguan sedikit pun.

Kehormatan menjadi asas yang begitu di perdulikan di dalam agama Islam, karena dengan kehormatan manusia bisa hidup dengan layak di muka bumi. Khususnya dalam kasus qadzaf, yang mana secara prinsipnya amat mengancam kehormatan manusia. Syari'at Islam menjatuhkan dua sanksi yang dipersiapkan bagi mereka: sanksi asli yang terbatas waktu, yang diberikan untuk fisik, yaitu dengan hukum dera sebanyak delapan puluh kali; sanksi abadi untuk eksistensi, bahkan menurut mazhab Hanafiyah dapat menyebabkan tidak dapat di terima kesaksianya sepanjang hidupnya sampai dia bertaubat. Dasar masalah ini terdapat dalam QS. an-Nur ayat 4 dan 23 yang artinya:

"Artinya: Dan orang-orang yang menuduh wanita-wanita yang baik-baik (berbuat zina) dan mereka tidak mendatangkan empat orang saksi, Maka deralah mereka (yang menuduh itu) delapan puluh kali dera, dan janganlah kamu terima kesaksian mereka buat selama-lamanya. dan mereka Itulah orang-orang yang fasik." (Q.S an-Nur ayat 4) $)^{12}$

"Sesungguhnya orang-orang yang menuduh wanita yang baik-baik, yang lengah lagi beriman (berbuat zina), mereka kena la'nat di dunia dan akhirat, dan bagi mereka azab yang besar." (QS. an-Nur ayat 23$)^{13}$

Juga terdapat pada hadist Nabi Muhammad SAW, yaitu:

"Hendaklah kalian menghindari tujuh dosa yang dapat menyebabkan kebinasaan." Dikatakan kepada beliau, "Apakah ketujuh dosa itu wahai Rasulullah?". Beliau menjawab: "Dosa syirik (menyekutukan Allah), sihir, membunuh jiwa yang diharamkan oleh Allah untuk dibunuh kecuali dengan alasan yang benar, memakan harta anak yatim, memakan riba, lari dari medan perang, dan menuduh wanita mukminah baik-baik berbuat zina." (HR. Al-Bukhari No. 2560 dan Muslim No. 129).

Selain dalam persoalan qadzaf, Islam juga melarang perilaku-perilaku yang mana dapat mengancam perlindungan kehormatan, seperti menggunjing, mengadu domba, mengumpat, mencaci, memanggil dengan julukan tidak baik, dan perbuatan-perbuatan sejenis yang menyentuh kehormatan atau kemuliaan manusia. Seperti firman Allah SWT pada QS. Al-Hujurat ayat 11-12 dan QS. AlQalam ayat 10-12 yang artinya:

"Hai orang-orang yang beriman, janganlah sekumpulan orang laki-laki merendahkan kumpulan yang lain, boleh Jadi yang ditertawakan itu lebih baik dari mereka. dan jangan pula sekumpulan perempuan merendahkan kumpulan lainnya, boleh Jadi yang direndahkan itu lebih baik. dan janganlah suka mencela dirimu sendiridan jangan

${ }^{11 G a l u h ~ N a s h r u l l a h ~ K a r t i k a ~ M a y a n g s a r i ~ R ~ d a n ~ H . ~ H a s n i ~ N o o r, ~ K o n s e p ~ M a q a s h i d . . ., ~ h . ~} 138$.

12Departemen Agama RI, Al-Qur'an dan Terjemahnya, (Bandung: CV. Diponegoro, 2005), h. 279.

13Ibid., h. 281 
memanggil dengan gelaran yang mengandung ejekan. seburuk-buruk panggilan adalah (panggilan) yang buruk sesudah imandan Barangsiapa yang tidak bertobat, Maka mereka Itulah orang-orang yang zalim. Hai orang-orang yang beriman, jauhilah kebanyakan purba-sangka (kecurigaan), karena sebagian dari purba-sangka itu dosa. dan janganlah mencari-cari keburukan orang dan janganlah menggunjingkan satu sama lain. Adakah seorang diantara kamu yang suka memakan daging saudaranya yang sudah mati? Maka tentulah kamu merasa jijik kepadanya. dan bertakwalah kepada Allah. Sesungguhnya Allah Maha Penerima taubat lagi Maha Penyayang. (QS. Al-Hujurat ayat 11-12)14

"Dan janganlah kamu ikuti Setiap orang yang banyak bersumpah lagi hina, 11. Yang banyak mencela, yang kian ke mari menghambur fitnah, 12. Yang banyak menghalangi perbuatan baik, yang melampaui batas lagi banyak dosa" (QS. Al-Qalam ayat 10-12)15

Jika dihubungkan pada kontek surat al isra' ayat 32 yang mana subtansi ayat itu pada larangan terhadap zina, maka ada sisi kehormatan yang dijaga dari larangan ayat tersebut. Zina dengan segala konsekwensinya merupakan dosa yang dapat menodai kehormatan pelaku itu sendiri dan juga kehormatan norma sosial. Pada daasarnya agama mana pun, peradaban manapun tidak ada yang secara terang terangan menghalalkan zina, sehingga prinsip ini yang kemudian menjadikan seorang yang melakukan zina termasuk pada proses yang dapat mengancam kehormatan.

\section{C.3. Maqāṣid Syarī'ah Perlindungan Keturunan}

Islam mengarahkan kadar perhatianya yang besar untuk mengukuhkan aturan dan membersihkan keluarga dari cacat lemah, serta mengayominyadengan perbaikan dan ketenangan yang menjamin kehidupanya. Islam tidak meninggalkan satu sisi pun melainkan mendasarkanya di atas peraturan yang bijaksana, serta menghapus cara cara yang tidak lurus dan rusak yang dijalani syariat-syariat terdahulu dalam masalah ini.

Ketika nasab merupakan fondasi kekerabatan dalam keluarga dan penopang yang, yaitu akidah, akhlak, dan syariat. antar anggotanya, maka Islam memberikan perhatianya yang sangat besar untuk melindungi nasab dari segala sesuatu yang menyebabkan pencampuran atau yang menghinakan kemuliaan nasab tersebut. ${ }^{16}$ Nasab yang telah menjadi bahasa Indonesia dan telah masuk dalam kamus besar bahasa Indonesia itu diartikan sebagai keturunan atau pertalian keluarga. ${ }^{17}$ Sedangkan dalam ensiklopedia Islam, nasab diartikan sebagai keturunan atau kerabhat, yaitu pertalian keluarga melalui akad nikah perkawinan yang sah. ${ }^{18}$

Nasab secara terminology adalah pertalian kekeluargaan berdasarkan hubungan darah, baik ke atas, ke bawah, ataupun ke sampingyang semua itu merupakan salah satu akibat dari perkawinan yang sah, perkawinan yang fasid dan hubungan badan yang subhat. ${ }^{19}$

${ }^{14}$ Departemen Agama RI, Al-Qur'an dan Terjemahnya..., h. 412.

15Ibid., h. 451.

16 Ibid., h 143.

17Dapertemen PendidikanNasional, Kamus Besar Bahasa Indonesia, (Jakarta, Balai Pustaka, 1998), cetakan I, h. 609.

18Ensiklopedi Islam, h. 13.

${ }^{19}$ Nurul Irfan, Nasab dan Status Anak dalam Hukum Islam, (Jakarta: Amzah, 2012), h. 32. 
Para ulama sepakat bahwa hukum Islam dibentuk dalam rangka mewujudkan dan memelihara kemaslahatan manusia, baik secara individu maupun secara koolektif. Maslahat yang ingin diwujudkan adalah keseluruhan aspek kepentingan manusia.

Maslahat yang berarti damai dan tentrram. Damai berorientasi pada fisik. Sedangkan tentram berorentasi pada psikis. Artinya maslahat secara terminologi adalah perolehan manfaat dan penolakan terhadap kerusakan. ${ }^{20}$ Maslahah terdapat tiga macam, yakni maslahah mu'tabarah, maslahah mursalah, dan maslahah mulgat.

Maslahah mu'tabarah diklasifikasikan menjadi tiga tingkatan, dhoruriyah, hajiyah, dan tahsiniyah. Maslahah yang masuk pada kelompok pertama adalah lima tujuan agama (maqashid syari'ah), yaitu dalam rangka menjaga agama, jiwa, akal, harta dan keturunan. ${ }^{21}$

Hal yang menjadi prinsip yang akan dibahas kali ini ialah nasab atau keturunan. Dalam rangka menjaga nasab inilah agama Islam melarang segala bentuk perzinaan dan porstitusi serta sangat menganjurkan nikah untuk melangsungkan keturunan umat manusia agar tidak punah dan mempunyai hubungan kekerabatan yang sah dan jelas.

Dari uraian di atas dapat diketahui bahwa tujuan terakhir dari disyariatkannya ajaran agama Islam adalah untuk memelihara dan menjaga keturunan atau nasab, ulama fiqh mengatakan bahwa nasab adalah merupakan salah satu fondasi yang kokoh dalam membina suatu kehidupan rumah tangga yang bisa mengikat antara pribadi berdasarkan kesatuan darah. ${ }^{22}$

Dalam rangka menjjaga nasab atau keturunan inilah ajaran agama Islam mensyariatkan niukah sebagai cara dipandang sah untuk menjaga dan memelihara kemurnian nasab. Islam memanddang bahwa kemurnian nasab sangat penting, karena hukum Islam sangat terkait dengan struktur keluarga, baik hukum perkawinan, maupun kewarisan dengan berbagai derivasinya yang meliputi hak hak perdata dalam hukum Islam, baik menyangkut hak nasab, hak perwalian, hak memperoleh nafkah dan hak mendapatkan warisan, bahkan konsep ke-mahram-an atau kemuhriman dalam Islam akibat hubungan persemendaan atau perkawinan. Bersamaan dengan perintah nikah, dalam hukum Islam juga diharamkan mendekati zina, karena zina menyebabkan tidak terpeliharanya nasab secara sah.

Dalam rangka memelihara nasab ini di syariatkanlah nikah sebagai cara yang dipandang sah untuk menjaga dan memelihara Kemurnian nasab. Adapun tujuan mendasar dari sebuah pernikahan adalah untuk melangsungkan hidup dan kehidupan serta keturunan umat manusia sebagai khalifah dimuka bumi. Tentunya manusia sangat mengidamkan keluarga yang pennuh dengan kasih saying, kasih saying antara suami, istri, beserta anak anaknya. Sehingga dalam pembinaan keluarga yang seperti ini Allah menjadikan nasab sebagai sarana utamanya. Bahkan nasab merupakan karunia dan nikmat paling besar yang diturunkan oleh Allah SWT. Di samping itu nasab juga merupakan hak paling pertama yang harus diterima oleh seorang bayi agar terhindar dari kehinaan dan ketelantaran.

${ }^{20}$ Asy-Syatibi, Al;Muwafaqot fi ushul Al-Ahkam,(Mesir: Dar Al-Fikr, 1341 H), jilid2, h. 2.

21Ibid., h. 5

22 Nurul Irfan, Nasab dan Status..., h. 8 
Terlepas dari hak anak, nasab dalam perkawinan menjadi salah satu faktoor yang perlu di pertimbangkan untuk memilih pasangan, yang mana dikenal dengan istilah kafa'ah. Hal ini dimaksudkan agar tujuan perkawinan bisa tercapai, yaitu ketenangan hidup berdasarkan cinta dan kasih sayang.

Al-Bukhari meriwayatkan dari Abu Hurairah Radhiyallahu anhu, dari Nabi Shallallahu 'alaihi wa sallam, beliau bersabda:

"Wanita dinikahi karena empat hal, karena harta, kemuliaan (keturunan), kecantikan, dank arena agamanya. Maka pilihlah agamanya sebab akan menguntungkan kamu"

Konsep ini adalah salah satu keniscayaan yang menjadi tujuuan hukum Islam. Al-„,Amiri menyebutkan hal tersebut pada awal usahanya untuk menggambarkan teori Maqasid kebutuhan dengan istilah "hukum bagi tindakan melanggar kesusilaan". Al-Juwairi mengembangkan "teori hukum pidana" (mazajir) versi Al-,,Amiri menjadi “teori penjagaan” („,ismah) yang diekspresikan oleh Al-Juwaini dengan istilah "hifz al-furuj" yang berarti menjaga kemaluan. Selanjutnya, Abu hamid Al-Gazali yang membuat istilah hifz al-nasl (hifzunnasli) sebagai Maqasid hukum Islam pada tingkatan keniscayaan, yang kemudian diikuti oleh Al-Syatibi. Pada abad ke XX (dua puluh) Masehi para penulis Maqasid secara signifikan mengembangkan "perlindungan keturunan" menjadi teori berorientasi keluarga. Seperti Ibn "Asyur menjadikan "peduli keluarga" sebagai Maqasid hukum Islam. Hal ini dijelaskan dalam monografinya, „Usul Al-Nizam Alljtima“ i fi Al-Islam (Dasar-dasar Sistem Sosial dalam Islam) yang berorientasi pada keluarga an nilai-nilai mora dalam hukum Islam. Kontribusi Ibn "Asyur membuka pintu bagi para cedekiaan kontemporer untuk mengembangkan teori Maqasd dalam berbagai cara baru. Orientasi pandangan yang baru tersebut bukanlah teori hukum pidana (muzajirr) versi AlAmiri maupun konsep perlindungan (hifz) versi Al-Gazali, melainkan konsep "nilai dan sistem" menurut terminologi Ibn Asyur. ${ }^{23}$

\section{Simpulan}

Nas pelarangan zina maka dapat diketahui jenis maslahah yang terkandung di dalamnya ialah maslahah mu'tabarah. Dengan melihat ada salah satu tujuan hukum Islam, yakni menjaga kehormaran dan keturunan, yang mana menjaga dari hal yang merusak keturunan yaitu perilaku zina. Syariat Islam melarang zina dengan teks jangan mendekati zina, adapun larangan zina ini demi terjaganya keturunan. Sementara, dalam perilaku zina(sebagai maqashid syariah yang primer) terdapat hal hal yang dapat mengantarkannya, seperti halnya berciuaman, meraba raba anggota tubuh, saling memandang, membuka sebagian aurot (sebagai maqashid syariah yang sekunder). Melihat uraian di atas maka Relevansi maqashid syari'ah ialah menjaga kehormatan. Dengan menjaga kehormatan yakni dilarangnya hal-hal yang dapat merusak kehormatan itu sendiri. Selain dari menjaga kehormatan ayat dilarang nya mendekati zina juga bermaksud menjaga nasab. Karena zina dapat merusak tatanan nasab dalam keluarga sehingga hal-hal yang mendekati zina juga dilarang untuk dilakukan. Ulama fiqh mengatakan bahwa nasab adalah merupakan salah satu fondasi yang kokoh dalam membina suatu kehidupan ruma tangga yang bisa mengikat antara

23Syahrul Sidiq, Maqasid Syari"ah \& Tantangan Modernitas: Sebuah Telaah Pemikiran Jasser Auda,( IN RIGHT Jurnal Agama dan Hak Azazi Manusia, Vol. 7, No. 1, November 2017), h. 155. 
pribadi berdasarkan kesatuan darah. Dalam rangka menjaga nasab atau keturunan inilah ajaran agama Islam mensyari'atkan nikah sebagai cara yang dipandang sah untuk menjaga dan memelihara kemurnian nasab. Islam memandang bahwa kemurnian nasab sangat penting, karena hukum Islam sangatterkait dengan struktur keluarga, baik hukum perkawinan, maupun kewarisan dengan berbagai derivasinya yang meliputi hak perdata dalam hukum Islam, baik menyangkut hak nasab, hak perwalian, hak memperoleh nafkah dan hak mendapatkan warisan, bahkan konsep ke-mahram-an atau kemuhriman. Bersamaan dengan perintah nikah, sebagai perintah syara' dalam menjaga nasab Islam juga melarang mendekati zina karena menyebabkan tidak terpeliharanya nasab secara sah.

\section{Referensi:}

Abd 'Athi' Muhammad Ali. al-Maqhosid asy-Syar`iyyah wa Atsaruha fi al-Fiqh al-Isllami. Kairo: Dar al-Hadits, 2007

Abd. Djalal. Afifuddin Muhajir. Maslahah sebagai Cita Moral bagi Pembentukan Hukum Islam. Situbondo. Ibrahimy Press, 2010

Abdul Hayat. Ushul Fiqh: Dasar-dasar untuk Memahami Fiqh Islam. Jakarta: Rajawali Pers, 2016

Abdul Manan. Pembaruan Hukum Islam di Indonesia. Jakarta: Kencana, 2017

Abdul Wahab Khalaf.Ilmu ushul fiqh. Semarang: Toha PutraGroup, 1994

Abdurrahmat Fathoni. Metodologi Penelitian \& Teknik Penyusunan Skripsi. Jakarta: Rineka Cipta, 2011

Abu Ishaq al-Syathibi. al-Muwafaqad fi Ushulal-Syari'ah. Beirut: Dar al-KutubalIlmiyah, 2003

Ahmad Al-Mursi Husain Jauhar. Maashid Syariah.Jakarta: Amzah, 2013

Ahmad Muhammad Assaf. Al-Ahkam Al-Fiqhiyah Fi Madzahib Al-Islamiyah Al-Arba'ah. Beirut: Dar Ihya'I Al-Ulum, 1998

Ali Mutaqin. Teori Maqashid Al Syariah dan Hubungannya dengan Metode Istinbath Hukum. Kanun Jurnal Ilmu Hukum. Vol, 19. No. 3. Agustus, 2017. pp. 547-570.

Amir Syarifuddin. Ushul Fiqh. Jilid 2 Jakarta: Logos Wacana Ilmu, 1999

Arikunto. Prosedur Penelitian Suatu Pendekatan Praktik. Jakarta: Rineka Cipta, 2013

Azzumardi Azra, dkk. Ensiklopedi IslamJilid 2 . Jakarta. Ichtiar Baru Van Hoeve, 2003, Cetakan ke-11

Burhan Ashafa. Metode Penelitian Hukum. Jakarta: Rineka Cipta, 2013

Burhan Bungin. Metode Penelitian Kualitatif. Jakarta : Raja Grafindo Persada, 2003

Cholid Narbuko dan Abu Achmadi. Metodologi Penelitian. Jakarta: Bumi Aksara, 2013

Dapertemen Pendidikan Nasional, Kamus Besar Bahasa Indonesia. Jakarta. Balai Pustaka, 1998, Cetakan I

Departemen Agama RI. Al-Qur'an dan Terjemahnya. Bandung: CV. Diponegoro, 2005

Faqihudin Abdu Qodir. Nilai-Nilai Pluralisme Dalam Ajaran Sosial Islam Perspektif Fiqh Realitas. Dalam Jurnal Ulumuna. Vol.III. Edisi 5. No 2 Juli Desember 2004 
Galuh Nashrullah Kartika Mayangsari R dan H. Hasni Noor. Konsep Maqashid Al-Syariah Dalam Menentukan Hukum Islam Perspektif Al-Syatibi dan Jasser Auda Al-Iqtishadiyah.VOL. I. ISSUE I. desember 2014

Ghofar Shidiq. TeoriMaqashid Al-Syari'ah Dalam Hukum Islam. Jurnal Sultan Agung.Vol. XLIV No. 118 Juni - Agustus 2009

Hisyam bin Said Azhar. Maqhosid asy-Syari ah inda Imam al-Haramain wa Atsaruha fi at-Tasorrufat al-Maliyyah. Riyad: Maktabah ar-Rusyd, 2010

Huzaimah Tahido Yanggo. Masail Fiqhiyyah. Bandung. Angkasa, 2005

Imam Mustofa. Membangun Epistimolgi Fiqh Medis Melalui Kontekstualisasi Maqashid Syari'ah. Dalam Jurnal-Manhij. vol. IX no.2 Desember 2015

Manna al-Qathtan. Tarikh Tasyri' al-Islami. Kairo: Maktabah Wahbah, 2001

Moh. Ali Al-Sobuni. Sofwaatu al-Tafasir. Beirut: 'asriyah

Moh. Mukri. Rekonstruksi Hukum Islam Indonesia. Yogyakarta: Idea Press Yogyakarta, 2014

Neng Jubaidah. perzinaan dalam peraturan perundang-undangan di Indonesia ditinjau dari hukum Islam. Jakarta: kencana.2010

Nurul Irfan. Nasab \& Status Anak Dalam Hukum Islam. Jakarta: Amzah, 2012

Sapiudin Shidiq. Ushul Fiqh. Jakarta: Kencanan, 2017

Satria Efendi M.zein. Maqashid Syariah Dan Perubahan Sosial. Dalam DialogBalitbang Depag. No.33 Th. XV. Januari 1991

Satria Effendi. M.Zein. Ushul Fiqh. Jakarta: Kencana, 2017

Sugiyono. Metode Penelitian Kuantitatif. Kualitatif. R \& D. Bandung: Alfabeta, 2016

Sutrisno Hadi. Metodologi Research. Yogyakarta: Andi Offset, 2001 